\title{
Social Correlates of Nurses' Preparedness towards Retirement in Zaria, Northwest Nigeria
}

\author{
Anyebe $E^{1^{*}}$, Yamah $F^{2}$, Philip $F^{2}$, Lawal $H^{3}$ and Olarenwaju EO \\ ${ }^{1}$ Faculty of Health Sciences, National Open University of Nigeria, Abuja, Nigeria \\ ${ }^{2}$ School of Nursing, Ahmadu Bello University Teaching Hospital, Zaria, Nigeria \\ ${ }^{3}$ Department of Nursing Services, Ahmadu Bello University Teaching Hospital, Zaria, Nigeria
}

*Corresponding author: Anyebe EE, Department of Nursing Sciences, Faculty of Health Sciences, National Open University of Nigeria, Abuja, Nigeria, Tel: +2348036422771, E-mail: ejembianyebe@gmail.com; eanybe@noun.edu.ng

\begin{abstract}
This study assessed the level of preparedness of nurses toward retirement in two hospitals in Zaria. A descriptive non-experimental research design was used for the study. Using a questionnaire, data were collected from a convenience sample of 108 nurses. The data were analyzed descriptively using SPSS version 22 . The result showed that most of the nurses are aware of retirement plans and believe that retirement is important in nursing. Most of them $(60.2 \%)$ agree that there are benefits of early retirement, but a significant number $(31.4 \%)$ of the respondents wish to retire at 70 years and above. Majority (63\%) prepare for retirement by personal saving and contributing to Nigeria's compulsory contributory pension scheme. Male nurses, unmarried and younger nurses (in the age bracket 20-29 years) reported being to have more informed plan or even more prepared for retirement than their female, married and older counterparts. In conclusion, many nurses desire an elongation of age, to work longer in government establishments. Preparing more towards retirement is mainly by personal saving arrangements and statutory government pension scheme. Early planning for retirement from the point assuming duties through a combination of personal and institutional arrangements should form part of nurses' orientation as early as possible in their professional life.
\end{abstract}

\section{Keywords}

Developmental tasks, Nurses, Retirement preparedness, Nigeria

\section{Introduction}

Retirement is a planned process of leaving a job or career at or near the usual age for doing so; it is the period following the end of a person's working life [1].
Pension decree 102 of 1979 age constitution of the Federal Republic of Nigeria Section 3 (1) and (2) Stipulates the various types of retirement: Voluntary retirement or withdrawal after qualifying services, retirement after attaining the maximum statutory age of 60 years or length of service of 35 years. There are also retirements for the purpose of facilitating improved efficiency or economy or for public interest and retirement due to total or permanent disablement.

Retirement planning is an exercise in which people need to take necessary steps as soon as they enter the work force, because they have a brighter outlook with regards to their own financial future through early planning and well formulated retirement plan [2]. To avoid this pitfall experienced by many people, it is advisable to save money early in one's working career as one of the principles to overcome retirement crisis [3,4]. Atchley [5] developed six key principles of successful retirement planning. Believed to be the descriptive phases of retirement planning that represents a transitional process that individuals go through when they permanently leave work force, these principles include the need to: 1) Know yourself, 2) Understand the retirement vehicles available to you and use them wisely, 3) Choose the financial assets for those vehicles and invest wisely, 4) Know the retirement planning steps, 5) Develop a good retirement plan, write it well and follow it closely, and 6) Start TODAY. He clearly stated also that nurses get their information on retirement through other care givers (Nurses), Colleges in other fields, research, internet and articles from newspaper.

Citation: Anyebe EE, Yamah F, Philip F, Lawal H, Olarenwaju EO (2018) Social Correlates of Nurses' Preparedness towards Retirement in Zaria, Northwest Nigeria. Int Arch Nurs Health Care 4:090. doi. org/10.23937/2469-5823/1510090

Received: February 22, 2018: Accepted: March 29, 2018: Published: March 31, 2018

Copyright: (C) 2018 Anyebe EE, et al. This is an open-access article distributed under the terms of the Creative Commons Attribution License, which permits unrestricted use, distribution, and reproduction in any medium, provided the original author and source are credited. 
In addition, Nwakalu [2] suggested seven steps to financial preparation. These steps are to: 1) Set goal, 2) Estimate your current annual income available at retirement, 3) Estimate your total retirement needs after inflation to meet your goals, 4) Determine how much you have accumulated so far on a before-tax basis, 5) Determine the contribution or reduction to your retirement plans from your home, 6) Determine how much more you will need to save and 7) Determine your preferred retirement vehicles and save NOW. Other steps involve Pension Reform Act of 2004, active retirement life, accommodation in terms of housing, role change and a sound health.

Although lack of knowledge of these principles and steps affect retirement plans, several other factors have been reported to affect retirement plan. Mehbaliyev [6] classifies these factors at individual level (financial cost, assets, household size, health condition, behavioural activities) and country level (pension schemes and health care system). Miscinin [7] reports relationships between pension scheme, GDP and unemployment rate as institutional and macro variables and retirement plans. In specific social terms, Dorn and Sousa-Posa [8] implicate factors such as gender, marital status as being significantly related to early retirement plans. They also find that only retirement age and real per capita GDP have significant relationship. People with higher age have to involuntarily retire while people from per capita GDP go into retirement voluntarily or by their own. The English Longitudinal Study of Ageing [9] reports that retirement entails the economic, social, psychological and health elements. This study looks at the social factors of Nigerian nurses that are likely to affect their level of preparedness towards retirement at the individual level.

Social factors are reported to affect retirement plan, such as family size, additional responsibility of extended family, ostentatious life style lack of operational social security system for the aged preventing worker from accepting retirement, not to talk of planning towards it [10]. In a comparative study on the determinants of retirement status between old and new EU member States, Mehbaliyev [6], implicated gender, income and household sizes as significant factors. He established that in new EU States, males are less likely to be prepared for retirement compared to old States. This is associated with larger house sizes for which the male is much more responsible for the upkeep. The Nigerian worker is especially challenged by the problem of low income and high expenditure which invariably translates to low savings as well as financially draining the family and social responsibilities.

This study set out to find the individual nurse's factors that tend to influence their preparedness towards retirement from public service.

\section{Theoretical framework}

This study was guided by the theory of developmen- tal task; Harighurst (1972) as cited by Kozier and Erbs [11]. The theory holds that developmental task is a responsibility arising at or about a certain period in the life of an individual, successful achievement of which leads to his happiness in individual's disapproval by the society and difficulty with later task. Citing Erickson, Kozier and Erbs [11] also postulated some developmental choices of the middle ages as generativity versus stagnation. Retirement therefore needs to be planned for mentally, emotionally and financially because of this stage.

\section{Methodology}

\section{Design}

A descriptive cross-sectional survey design was adopted to study of level of preparedness of nurses towards retirement from two selected hospitals in Zaria.

\section{Setting, study population, sample size and sampling procedure}

Two hospitals, namely Ahmadu Bello University Teaching Hospital (ABUTH), Shika-Zaria and St. Luke's Hospital Wusasa-Zaria, were used for this study. They were purposively selected based on the researchers desire to have nurses' views on retirement plans from both government-owned and faith-based hospitals. Each hospital was stratified into wards or units of the two hospitals, from which four wards/units were randomly selected.

A total of 540 nurses (500 from ABUTH Zaria and 40 from St. Luke's Anglican Hospital Wusasa Zaria constituted the target population. Using at least $20 \%$ of the target population as suggested by Nwana [12], a convenient sample of 108 nurses was selected.

\section{Data collection tool and techniques}

A self-constructed-21-item questionnaire, consisting of two sections, $A$ and $B$, was used to obtain information from the respondents. Section $A$ (made up of six questions) was on the respondents' socio-demographic variables and Section B with fifteen questions focused on retirement issues. Data were collected through the personal involvement by the second author; this included the researcher administering the tool face to face and from ward to ward in the two hospitals.

\section{Ethical considerations}

Permission was sought from the authorities of each ward of the two hospitals, after submitting letter of introduction from the researchers' place of work. Participation by nurses was voluntary, after due explanation of the purpose of the study to respondents. An informed consent was thus obtained. Anonymity and confidentiality were strictly maintained.

\section{Data analysis}

The data collected were analyzed using both descriptive and inferential statistics. Data collected were 
Table 1: Socio-demographic characteristics of the respondents.

\begin{tabular}{|c|c|c|}
\hline Variables & Frequency $(\mathrm{N}=108)$ & Percentage (\%) \\
\hline \multicolumn{3}{|l|}{ Ages in years } \\
\hline $20-29$ & 32 & 29.6 \\
\hline $30-39$ & 18 & 16.7 \\
\hline $40-49$ & 25 & 23.1 \\
\hline $50-59$ & 33 & 30.6 \\
\hline 60 and above & 0 & 0 \\
\hline Total & 108 & 100 \\
\hline \multicolumn{3}{|l|}{ Gender } \\
\hline Male & 25 & 23.1 \\
\hline Female & 83 & 76.9 \\
\hline Total & 108 & 100 \\
\hline \multicolumn{3}{|l|}{ Marital status } \\
\hline Single & 37 & 34.3 \\
\hline Married & 60 & 55.6 \\
\hline Widow(er) & 8 & 7.4 \\
\hline Divorced & 3 & 2.7 \\
\hline Total & 108 & 100 \\
\hline \multicolumn{3}{|l|}{ Rank } \\
\hline SN & 24 & 22.2 \\
\hline NO & 20 & 18.5 \\
\hline SNO & 10 & 9.3 \\
\hline PNO & 12 & 11.1 \\
\hline ACNO & 22 & 20.4 \\
\hline CNO & 20 & 18.5 \\
\hline Total & 108 & 100 \\
\hline \multicolumn{3}{|c|}{ Religious affiliation } \\
\hline Christianity & 70 & 64.8 \\
\hline Islam & 38 & 35.2 \\
\hline Total & 108 & 100 \\
\hline \multicolumn{3}{|c|}{ Ethnic groups } \\
\hline Hausa & 23 & 22.3 \\
\hline Ibo & 15 & 14 \\
\hline Yoruba & 25 & 23.1 \\
\hline Others & 45 & 48.6 \\
\hline Total & 108 & 100 \\
\hline
\end{tabular}

Table 2: Awareness of nurses towards retirement plans.

\begin{tabular}{|l|l|l|}
\hline Response & Frequency & Percentage \\
\hline Yes & 90 & 83.3 \\
\hline No & 18 & 16.7 \\
\hline Total & 108 & 100 \\
\hline
\end{tabular}

first edited, coded and entered into Excel Spreadsheet. Socio-demographic variables were correlated with the level of preparedness.

\section{Results}

\section{Socio-demographic characteristics}

As shown in Table 1 , the ages of the respondents range from 20 to 60 years, with most (30.6\%) being between 50 and 59 years. Majority (76.9\%) were females, married and mostly Christians (64.8\%) from different ethnic extractions, including Yoruba (23\%). Professional rankings range from senior nursing officers to chief nursing officers, with the senior nursing officers constituting $22.2 \%$.

\section{Retirement preparedness and benefits}

Majority $(83.3 \%, n=90)$ of the nurses are aware of

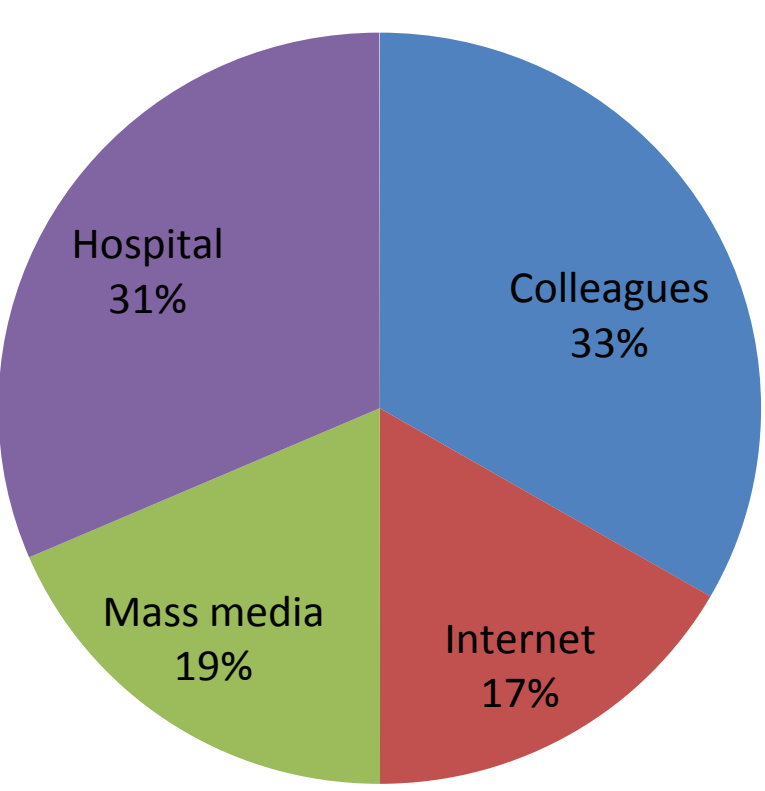

Figure 1: Sources of retirement information.

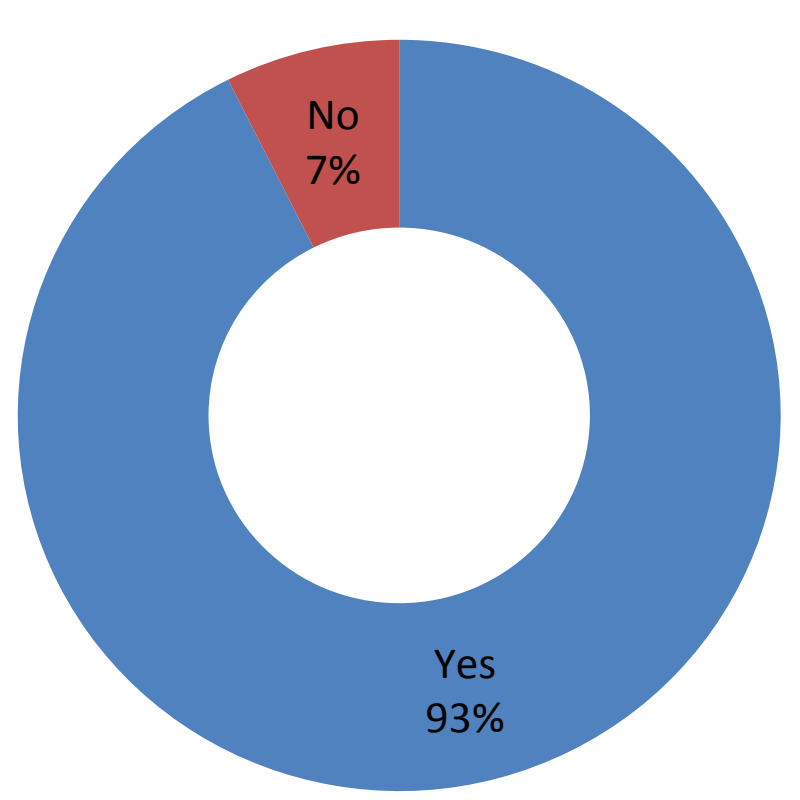

Figure 2: Is retirement preparation important?

retirement plans (Table 2), and obtained their retirement information from various sources such as colleagues (33\%) and hospitals (31\%) (see Figure 1). Most of the respondents $(92 \%)$ consider retirement plans as important practice in nursing while $8 \%$ think it is not (Figure 2). Fear of thinking about ageing and death are the main reasons given by some nurses for not seeing retirement preparation as necessary (see Figure 3).

Table 3 shows phases at which nurses start making retirement plans: $47.2 \%$ believe that one should start plans 5 years to retirement, while $1.9 \%$ is of the opinion that it should be after 20 years of service. Majority $(60.2 \%)$ however agrees that there are benefits of early retirement and out of this, $38.2 \%$ says it involves financial stability benefits.

On the desired accepted age to retire, a significant 


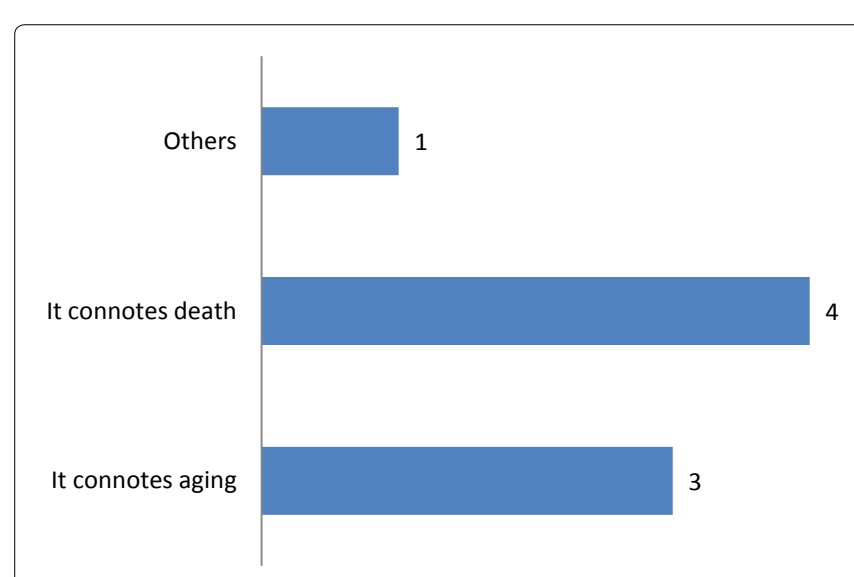

Figure 3: Reasons for considering retirement not important, $\mathrm{N}=8$.

Table 3: Phase nurses start making retirement plans.

\begin{tabular}{|c|c|c|}
\hline Variable & $\begin{array}{l}\text { Frequency } \\
(\mathrm{N}=108)\end{array}$ & $\begin{array}{l}\text { Percentage } \\
(\%)\end{array}$ \\
\hline \multicolumn{3}{|c|}{ Time to prepare for retirement: } \\
\hline $\begin{array}{l}\text { As soon as you enter the } \\
\text { work force }\end{array}$ & 50 & 46.3 \\
\hline After 10 years of service & 4 & 3.7 \\
\hline After 20 years of service & 2 & 1.9 \\
\hline 5 years to retirement & 51 & 47.2 \\
\hline On retirement & 1 & 0.9 \\
\hline \multicolumn{3}{|c|}{ Benefits of early retirement } \\
\hline Yes & 65 & 60.2 \\
\hline No & 43 & 39.8 \\
\hline \multicolumn{3}{|c|}{ Involvement of the hospital in pre-retirement education } \\
\hline Yes & 49 & 45.4 \\
\hline No & 59 & 54.6 \\
\hline \multicolumn{3}{|c|}{ Desired accepted age to retire by respondents } \\
\hline As soon as possible & 0 & 0 \\
\hline $41-45$ & 15 & 13.9 \\
\hline $51-60$ & 30 & 27.8 \\
\hline $61-70$ & 29 & 26.9 \\
\hline 71 and above & 34 & 31.4 \\
\hline \multicolumn{3}{|c|}{$\begin{array}{l}\text { The desired ideal retirement age willingness to retire at } \\
60\end{array}$} \\
\hline Yes & 53 & 49.1 \\
\hline No & 55 & 50.9 \\
\hline \multicolumn{3}{|c|}{ Financial preparation for retirement } \\
\hline Yes & 68 & 63 \\
\hline No & 40 & 37 \\
\hline \multicolumn{3}{|c|}{ Retirement sources of income } \\
\hline Personal savings & 45 & 38.1 \\
\hline Work pension & 25 & 21.2 \\
\hline Government pension & 30 & 25.4 \\
\hline Yet to decide & 18 & 15.3 \\
\hline
\end{tabular}

number (31.4\%) of the respondents wish to retire at 70 years and above. Slightly more than half (50.9\%) did not specify at what age they would want to retire but were not willing to retire at 60 .

The study further showed the respondents' reasons for unwillingness to retire at 60 . These included lack of retirement plans $(31.5 \%)$, and the retirement age being too short (29.6\%). Majority (63\%) of the respondents are inherently saving money sufficient for their retire- ment plans apart from contributing pension scheme and this through personal savings (38.1).

An analysis of the relationship between the socio-demographic attributes of nurses and level of preparedness towards retirement shows that male nurses and younger nurses (in the age bracket 20-29 years) are more prepared or have more informed plan for retirement (Table $4 \mathrm{a}$ and Table $4 \mathrm{~b}$ ). Similarly, data shows that the singles and the junior cadre nurses (SN to PNO) are preparing towards retirement more (Table $4 \mathrm{c}$ and Table $4 d)$.

\section{Discussion}

The study participants were predominantly females (76.9\%) aged 50-59 years, implying that most of the nurses should be approaching their retirement age of 60 years [13], and achieving the developmental task as stated by Havighurst (1972) as cited in Kozier and Erbs [11]. It was also observed that both junior and senior constitute equal proportion for this study. This is to make comparison between the two categories of nurses more scientific and acceptable (Table 2).

The findings of this study revealed that majority (83.3\%) of the respondents have thought of retirement plans. About one third had their information on retirement from their colleagues. It also showed that most see retirement as an important aspect in nursing which agrees with Ayeni [14] who stated that every worker that has worked hard in life needs rest. Ayeni [14] had observed that retirement planning is not practiced by many because people associate retirement plans to aging, which many believe connote failing health. This is in line with the findings in this study where almost half of the respondents that believe retirement are not an important practice among nurses because it connotes death.

Unlike Nwakalu's [2] position, that retirement planning should start as soon as one enters the work force, $47.2 \%$ of respondents in this study stated that retirement planning should start 5 years to retirement. However, majority (54.6\%) acknowledged the benefits in early retirement. Findings in this study showed that, some $(38.2 \%)$ of the respondents think the most important benefit of early retirement is financial stability. Ayeni [14] agree that the most important factor that guarantees good quality of life after retirement is financial stability because it will determine the kind of life one lives, family stability, housing, healthy living, and decreased social responsibility. Ribero and Blakeley [3] similarly reported that most nurses prepared for retirement mainly by financial accumulation. However, lack of planning can cause untold hardships at retirement [15].

The study further showed that some of the respondents believe that retirement age is 70 years. This is con- 
Table 4: The socio-demographic attributes and level of preparedness towards retirement.

\begin{tabular}{|l|l|l|l|}
\hline Variables & Prepared (\%) & Unprepared (\%) & Total (\%) \\
\hline Gender: & $25(100)$ & $0(0)$ & $25(100)$ \\
\hline Male & $40(48.2)$ & $43(51.8)$ & $83(100)$ \\
\hline Female & 65 & 43 & 108 \\
\hline Total & $31(96.6)$ & $1(3.1)$ & $32(100)$ \\
\hline Age (in years): & $8(44.4)$ & $10(55.6)$ & $18(100)$ \\
\hline $20-29$ & $16(6.4)$ & $9(3.6)$ & $25(100)$ \\
\hline $30-39$ & $10(30.3)$ & $23(69.7)$ & $33(100)$ \\
\hline $40-49$ & 65 & 43 & 108 \\
\hline $50-59$ & & $12(32.4)$ & $37(100)$ \\
\hline Total & $25(67.6)$ & $40(66.7)$ & $60(100)$ \\
\hline Marital status: & $20(33.3)$ & $0(00)$ & $3(100)$ \\
\hline Single & $3(100)$ & $0(00)$ & $8(100)$ \\
\hline Married & $8(100)$ & 52 & 108 \\
\hline Divorced & 56 & & $54(100)$ \\
\hline Widow(er) & & $1(1.9)$ & $54(100)$ \\
\hline Total & $53(98.1)$ & $42(77.8)$ & 108 \\
\hline Rank: & $12(22.2)$ & 43 & \\
\hline Junior Cadre (SN-SNO) & 65 & & \\
\hline Senior Cadre (PNO-ADN) & & & \\
\hline Total & & & \\
\hline
\end{tabular}

trary to the current stipulated age of retirement by the government: Pension Reform Act [16] states that, the ideal retirement age is 60 years of age. The unwillingness of more than half of the nurses interviewed (50.9\%) to retire at 60 years, coupled with the lack of retirement plans as expressed by many nurses $(31.5 \%)$ is a nightmare to most Nigerian nurses, as feared by Adeline [10] in an earlier assertion. This fear is probably due to the poor and unreliable pension schemes in the most developing countries including Nigeria [14]. However, many of those planning for retirement $(63 \%)$ are savings at a sufficient rate for retirement in forms of personal savings. All the male nurses are better prepared for retirement than the females. Studies by Mehbaliyev [6] established similar findings in new EU Member States. In addition, large household sizes have also been found to be determinants of retirement preparedness. However, the same study also reported that contrasting findings in old EU Member States. The finding also noted that young, single and junior cadre nurses are thinking of retirement more than others. Contrary to this finding, in their study, Ribero and Blakeley [3] found that both nurse managers (senior nurses) and junior nurses prepared equally.

\section{Conclusion}

The study focused on the level of preparedness of nurses towards retirement in two selected hospitals in Zaria metropolis. The results showed that in spite of high awareness level about retirement, more than half of the nurses are not prepared for retirement. For those prepared, male nurses reported better retirement plans than their female counterparts. Similarly, younger nurses (in terms of age and rank) appear more conscious of retirement plans than the older/more senior nurses. Many nurses desire an extension of the 60 years retire- ment age to be elongated to between 65 and 70 years (to enable them work longer). The general level of preparedness is low.

\section{Recommendations}

Based on the findings of this study, the following are recommended:

i. Proper enlightenment to nurses on retirement should start as soon as nurses are employed;

ii. Pre-employment education and programmes by individual hospitals to enlighten the nurses on the need for early and well prepared retirement;

iii. Retirement information should be included in Mandatory Continuing Professional Development Programme (MCPDP) for nurses, where the culture of saving is encouraged.

\section{References}

1. Premium Encarta (2009) Definition of Retirement. Microsoft Corporation.

2. Nwakalu H (2011) Retirement Planning. The Punch Newspaper 4.

3. Blakeley J, Ribeiro V (2008) Are nurses prepared for retirement? J Nurs Manag 16: 744-752.

4. Anonymous (2011) Problem of unplanned retirement.

5. Atchley RC (2000) Social forces and aging.

6. Mehbaliyev R (2011) Determinants of retirement status: Comparative evidence from old and new EU member States. Central European Univeristy, Budapest, Hungary.

7. Miscinin L (2007) Retirement in Western Europe: Evidence form Ten Europen Countries. Central European University.

8. Dorn D, Sousa-Posa A (2005) Early retirement: Free choice or forced decision. CESifo Working Paper Series No. 1542.

9. The English Longitudinal Study of Ageing (ELSA). 
10. Adeline A (2010) A simple way of planning for retirement. The National Newspaper 7.

11. Kozier M, Erbs G (2008) Fundamentals of Nursing. Pearson Publishers, UK, 353-356.

12. Nwana OC (1981) Introduction to Educational Research. Heineman Educational Books (Nig. Ltd), Ibadan.

13. Nigerian Constitution on Pension and Retirement (2002) Pension Reform Act.
14. Ayeni EO (2003) Continuing Education Programme for Nurses. (1 $1^{\text {st }}$ edn), School of Nursing ABUTH, Zaria, 103105.

15. Anderson M, Ferguson F (2000) Retirement can damage your health. Nursing Mirror 159: 45.

16. (2004) Pension Reform Act. Nigeria. 